Molekul, Vol. 5. No. 2. Nov, 2010 : 75 - 82

\title{
DEKOLORISASI LIMBAH BATIK TULIS MENGGUNAKAN JAMUR INDIGENOUS HASIL ISOLASI PADA KONSENTRASI LIMBAH YANG BERBEDA
}

\author{
Ratna Stia Dewi, Sri Lestari \\ Fakultas Biologi, Universitas Jenderal Soedirman
}

\begin{abstract}
Azo as batik dyes are textile dyes which difficult to degradate. Fungus as bioremidiation organism are choosed to decolorize the dyes because its transformation ability, it can degradate toxic dyes component. The aim of research are to explore the fungus from Sokaraja-Banyumas batik industrial dyestuff, to know potential indigenous species wich can degradate it, to know dyestuff consentration which is degradated.

Result of research showed that the isolation process of indigenous fungi from batik dyestuff in District Sokaraja Banyumas produce 4 isolates that have the potential dekolorization, they are 3 isolates of the genus Fusarium, and 1 isolate of the genus Aspergillus. That indigenous fungus can be used to decolorize dyestuff batik the decolorize percentage $69.346 \%-82.421 \%$.
\end{abstract}

Keyword : batik dyestuff, dekolorization, indigenous fungus.

\section{Pendahuluan}

Pangsa pasar batik tulis banyumasan yang tak pernah reda semakin menyuburkan usaha industri batik di di Kecamatan Sokaraja Kabupaten Banyumas. Disamping itu permasalahan limbah warna yang ditimbulkannya belum bersolusi. Tiap rumah produksi mengalirkan sejumlah air berwarna setiap harinya untuk kemudian dibuang ke badan air di lingkungan pemukiman dan akan berdampak buruk bagi kesehatan masyarakat. Shore (1996) menyatakan, limbah industri yang berwarna tidak hanya menimbulkan polusi secara visual, tetapi dapat menimbulkan resiko kerusakan lingkungan dan kesehatan. Berdasarkan survey ETAD (Ecological and Toxicological Association of the Dyestuff Manufacturing Industry) diatas 90\% hasil tes dari 4000 bahan pewarna menunjukkan nilai $\mathrm{LD}_{50}$ lebih besar dari $2 \times 10^{3} \mathrm{mg} / \mathrm{kg}$. Nilai toksisitas tertinggi ditemukan pada bahan pewarna basa dan Diazo direct- salah satu jenis dari pewarna azo. Menurut Anonim (1996) pewarna azo bersifat nontoksik bagi tubuh manusia tetapi bisa menyebabkan reaksi alergi, dan beberapa produk degradasi pewarna azo (22-amina aromatik) kemungkinan karsinogenik dan merupakan amina aromatik yang menyebabkan resiko besar pada kesehatan.

Zat warna azo adalah bahan pewarna utama industri tekstil yang tergolong bahan kimia yang sulit terdegradasi. Menurut Dainfith (1997), Ayres dan Hellies (1999) struktur azo sebagai komponen atau senyawa azo adalah senyawa organik yang mengandung gugus $-\mathrm{N}=\mathrm{N}$ - terikat pada dua gugus lain. Menurut Suntoro (1983) zat warna harus terdiri dari kromofor dan auksokrom. Zat warna golongan azo merupakan golongan zat warna yang memiliki kromofor $-\mathrm{N}=\mathrm{N}$, triazo adalah zat warna senyawa organik kompleks golongan azo yang mengandung 3 kromofor $-\mathrm{N}=\mathrm{N}$. Kromofor adalah senyawa kimia yang memberikan warna, 
bukan sebagai zat warna karena kain yang terkena pewarna ini akan terwarnai sementara dan tidak permanen. Kromofor akan tetap terikat dalam bahan bila ada radikal yang mengikatnya yaitu auksokrom. Ikatan keduanya yang kuat menyebabkan zat warna azo tidak dapat hilang dari perairan. Azo merupakan pewarna yang banyak digunakan oleh para pengrajin batik di wilayah kabupaten banyumas karena sifatnya yang memiliki warna-warna terang khas batik banyumasan.

Menurut Awaluddin et al. (2001), pada tahun 1995 Seong et al. menyatakan bahwa bahan pewarna dapat didekolorisasi dengan metode fisika dan kimia, metode ini efektif namun karena biaya tinggi, menghasilkan senyawa berbahaya, masalah operasional dan membutuhkan perlengkapan intensif. Andayani dan Sumartono (1999) mengemukakan bahwa penggunaan senyawa kimia seperti karbon aktif hanya mampu menyerap pencemar yang mempunyai sifat non-polar dengan berat molekul rendah, sedangkan senyawa nonpolar dengan berat molekul tinggi tidak tereliminasi. Metode biologi digunakan sebagai metode alternatif, dianggap lebih menguntungkan karena lebih murah, ramah lingkungan dan tidak menghasilkan limbah tambahan berupa sedimentasi lumpur dalam jumlah besar. Perlakuan secara biologi salah satunya dengan menggunakan teknik bioremidiasi. Menurut Sullia (2000), bioremidiasi adalah teknologi kontrol polusi yang menggunakan sistem biologi untuk mengkatalisis degradasi atau transformasi dari banyak jenis bahan kimia toksik untuk dihilangkan bentuk kerugiannya. Bioremidiasi sama artinya dengan menggunakan sistem biologi untuk degradasi komponen toksik di dalam lingkungan.

Sistem biologi yang banyak digunakan yaitu memanfaatkan aktivitas organisme untuk menghancurkan bahan- bahan yang ada dalam air limbah menjadi bahan yang mudah dipisahkan atau memberi efek pencemaran rendah (Sumarno dan Sumantri, 1999). Organisme yang biasa digunakan adalah bakteri dan jamur. Penggunaan bakteri dalam pengolahan limbah cair secara efisien dapat menyerap logam - logam berat dan radionuklida dari lingkungannya (Gadd, 1992). Sani dan Banerjee (1999) mengemukakan bahwa penggunaan bakteri memiliki kelemahan yaitu semakin tinggi konsentrasi azo maka daya pendekolorisasian warna oleh bakteri semakin rendah. Robinson et al. (2001) menambahkan bahwa penggunaan bakteri tidak memungkinkan untuk mengolah limbah tekstil dalam volume besar sebab pertambahan biomassa dari bakteri relatif rendah dibandingkan dengan jamur sehingga tidak mampu mengimbangi jumlah volume limbah yang terlalu besar.

Jamur dipilih sebagai salah satu organisme bioremidiasi yang mampu mendegradasi komponen warna yang bersifat toksik karena jamur mempunyai kemampuan untuk transformasi yaitu suatu perubahan dari bahan kimia berbahaya yang terbentuk pada limbah (Sullia, 2000). Beberapa jenis fungi dapat hidup dengan baik pada $\mathrm{pH} 5$ dalam lingkungan limbah cair (Bitton, 1994). Penicillium, Geotrichum, Trichosporon, Cladosporium, Cephalosphorium, Trichoderma, Zoophagus, Arthrobotrys, Dactylaria, Sphaerotilus, dan fungi lainnya merupakan jenis- jenis fungi yang mampu hidup pada limbah cair khususnya pada pengolahan buangan dengan lumpur aktif (Suriawiria, 1996). Ada beberapa jenis fungi yang dapat diisolasi dari habitat misalnya pada tanah, lumpur limbah tekstil, salah satunya adalah Cochliobolus lunatus R. Nelson \& Haasis yang merupakan anamorf: Curvularia lunata (Tracy \& Earle) Boedjn. Jenis fungi yang diisolasi dari limbah tempat habitat asalnya yaitu 
perairan tercemar warna diperlukan sebagai sumber isolat untuk mendegradasi pewarna. Jenis fungi indigenus digunakan sebagai agen pendekolorisasi zat warna, selain diharapkan mempunyai ketahanan terhadap kondisi dibawah normal, juga memiliki kemampuan dalam mendegradasi pewarna azo. Fungi ini diharapkan tidak mati jika diberi perlakuan pada media yang didedahkan pewarna. Isolat ini diasumsikan telah teradaptasi oleh pewarna yang terkandung dalam limbah agar tidak diperlukan lagi fase pre-adaptasi yang memerlukan waktu relatif lama.

Purnamasari (2001) menyatakan, secara garis besar zat yang terkandung dalam limbah cair adalah 99,9\% air dan $0,1 \%$ padatan. Komponen kimia yang terkandung dalam limbah cair tekstil yaitu zat warna (dye stuff), sisa pewarnaan dan sisa pencucian (Atmaji et al., 1999). Tingkat kepekatan limbah mempengaruhi pertumbuhan jamur, maka perlu dilakukan penelitian tentang perlakuan yang mengkondisikan konsentrasi suspensi pada limbah sebagai media tumbuh jamur agar tetap menjadi media yang dapat digunakann jamur untuk tetap bertahan hidup.

Mekanisme pengolahan limbah oleh jamur dilakukan melalui proses degradasi dan absorpsi. Proses degradasi adalah proses penguraian senyawa komplek menjadi senyawa yang lebih sederhana oleh organisme sedangkan proses absorpsi adalah penyerapan limbah oleh gel pada miselium. Mekanisme degradasi dilakukan oleh lignin peroksidase, mangan peroksidase dan laccase. Ketiga enzim ini akan bekerja maksimal pada kondisi nitrogen rendah (Setiadi, 2002).

Dewi (2004) menyatakan, berdasarkan isolasi fungi dari limbah industri tekstil batik, yang diambil dari industri tekstil Perusahaan Batik Hadipriyanto Banyumas baik diambil dalam bentuk cair, lumpur serta tanah diperoleh 18 isolat fungi indigenous. Melalui kinerja skrining pada medium padat BAM (Basic Agar Medium) yang didedahkan pewarna Direct red 80 (azo) diperoleh satu isolat terbaik dari data nilai diameter miselium dan bobot kering miselium tertinggi sebagai parameter pertumbuhan tercepat. Isolat tersebut diidentifikasi berdasarkan warna koloni dan morfologi sel secara mikroskopis. Dilihat dari warna koloninya yaitu coklat kehitaman seperti beludru/ kapas dan dilihat dari morfologi selnya secara mikroskopis yaitu konidia warna coklat bentuk bersepta 3 membengkok disel ketiga yang lebih lebar dan berwarna lebih coklat, konidiofor tunggal/ kelompok dengan pigmentasi coklat kehitaman maka dinyatakan termasuk genus Curvularia (Barnett dan Hunter, 1972, Alexopoulos et al., 1996, dan Gandjar et al., 1999).

Kondisi limbah perusahaan tekstil berbeda dengan kondisi limbah industri kecil skala rumah tangga. Limbah perusahaan yang dibuang ke perairan telah mengalami beberapa jenjang pengolahan, industri kecil rumah tangga tentunya belum memiliki sistem pengolahan yang terpadu. Berdasarkan hal tersebut apakah dalam limbah yang belum diolah tersebut terkandung jamur dan bila ditemukan, bilakah jamur- jamur tersebut dapat digunakan untuk mendegradasi limbah yang masih mengandung warna yang nantinya isolat yang ditemukan dapat dikembangkan sebagai spesies indigenous unggulan yang mampu memecahkan permasalahan masyarakat atau lingkungan yang menjadi penduduk disekitar industriindustri kecil batik tulis di Kecamatan Sokaraja Kabupaten Banyumas. Kawasan ini dipilih sebagai objek studi karena belum ada penelitian yang pernah dilakukan dan letaknya yang cukup dekat dengan Unsoed selaku subyek penguji 
yang memiliki fasilitas Laboratorium penelitian yang diperlukan.

Kemampuan dekolorisasi dengan kecepatan yang berbeda dipengaruhi oleh faktor lingkungan yang mendukung pertumbuhan jamur, diantaranya adalah konsentrasi limbah sebagai media tumbuh jamur dan faktor $\mathrm{pH}$. Kepekatan limbah terjadi adanya suspensi yang terkonsentrasi didalamnya. Wisnuprapto et al. (1999) menyatakan, penggunaan zat warna azo dalam proses pewarnaan akan tertinggal sebanyak 60\% sebagai limbah. Secara fisik air limbah tekstil tampak keruh, dan berwarna (Widyantoro et al., 2000). Gabungan air limbah pabrik tekstil di Indonesia rata-rata mengandung 750 $\mathrm{mg} / \mathrm{l}$ padatan tersuspensi (Anonim, 2003). Kepekatan suspensi yang terkandung didalam limbah mempengaruhi pertumbuhan jamur. Semakin pekat konsentrasi limbah sebagai media tumbuh jamur semakin kecil kemungkinan jamur untuk dapat hidup.

Penelitian ini bertujuan untuk mengisolasi jamur indigenous dari buangan limbah industri- industri kecil batik tulis di Kecamatan Sokaraja Kabupaten Banyumas, dan mengetahui konsentrasi limbah yang dapat terdegradasi oleh jamur indigenous yang diperoleh.

\section{Metode Penelitian \\ Bahan dan Alat}

Bahan-bahan yang dipergunakan adalah beberapa media pertumbuhan yaitu: media Potato Dextrose Agar (PDA), dan media kultivasi (10 g Glukosa; 0,25 g Yeast ekstrak; $2 \mathrm{~g}$ $\mathrm{KH}_{2} \mathrm{PO}_{4} ; 0,5$ g $\mathrm{MgSO}_{4} .7 \mathrm{H}_{2} \mathrm{O} ; 0,8 \mathrm{Mm}$ $\mathrm{MnCl}_{2} .7 \mathrm{H}_{2} \mathrm{O} ; 0,1 \quad \mathrm{~g}$ Ammonium Phosphat; 0,5 $\mathrm{g} \mathrm{CaCl}_{2}, 20 \mathrm{ml}$ Sodium asetat; Aquades s/d $1000 \mathrm{ml}$ ), streptomycin, alkohol 70\%, spiritus, kapas, kertas label, wrapping, alumunium foil. Alat-alat yang dipergunakan adalah cawan petri, labu Erlenmeyer $100 \mathrm{ml}$ dan
$250 \mathrm{ml}$, labu seukuran, labu buchner, pipet tetes, pipet ukur, tabung reaksi, gelas piala, gelas ukur, spatula, pengaduk, pinset, jarum ose, bor gabus, rak, lampu spiritus, corong buchner, timbangan digital, magnetic stirer, $\mathrm{pH}$ meter, sentrifuge, spektrofotometer, pompa vakum, autoklaf, rotary shaker, incubator, kompor gas, almari pendingin, laminar air flow.

\section{Prosedur penelitian}

Sumber penelitian ini adalah isolat jamur indigenous yang di eksplorasi dari limbah warna batik tulis di Kecamatan Sokaraja Kabupaten Banyumas yang diisolasi menggunakan metode pengenceran. Untuk mendapatkan isolat jamur indigenous dalam penelitian ini diperoleh dari hasil isolasi beberapa limbah warna batik tulis yang ditumbuhkan dengan menggunakan medium Potato Dextrose Agar (PDA). Sampel diambil dari dibeberapa titik sampling berupa air, lumpur dan tanah. Isolat yang ditemukan diseleksi menggunakan medium padat yang mengandung pewarna batik. Isolat yang memiliki zona dekolorisasi dipilih untuk kemudian dipersiapkan sebagai inokulum yang ditumbuhkan pada medium kultivasi yang mengandung glukosa, yeast ekstrak, $\mathrm{MgSO}_{4} .7 \mathrm{H}_{2} \mathrm{O}, \mathrm{MnCl}_{2} .7$ $\mathrm{H}_{2} \mathrm{O}, \mathrm{CaCl}_{2}$, amonium phosphat, sodium asetat dengan pengaturan $\mathrm{pH}$ awal limbah. Suspensi yang mengandung pellet massa digunakan sebagai inokulum pada tabung Erlenmeyer berisi $100 \mathrm{ml}$ medium cair yang mengandung limbah dengan perlakuan konsentrasi $20 \%, 40 \%$, $60 \%, 80 \% 100 \%$. Inkubasi dilakukan menggunakan shaker kecepatan $150 \mathrm{rpm}$. Pengamatan dilakukan pada hari ke 2, 4, 6,8 dan seterusnya sampai limbah menjadi jernih. Adanya proses dekolorisasi diukur dengan menggunakan spektrofotometer dalam penghitungan Persentase Dekolorisasi yang diukur 
menurut rumus dari Awaluddin, et al. (2001) yang dimodifikasi :

$\%$ Dekolorisasi $=\frac{\text { konsentrasiawal }- \text { konsentrasiakhir }}{\text { konsentrasiawal }}$

\section{Hasil dan pembahasan}

Isolasi dari limbah batik tulis ditemukan 29 isolat jamur. Seleksi jamur dihasilkan empat isolat yang berpotensi sebagai pendekolorisasi limbah batik. Tiga isolat diidentifikasi masuk dalam genus Fusarium, dan 1 isolat adalah genus Aspergillus. Selanjutnya isolat genus Fusarium 1 disebut sebagai isolat 1, isolat genus Fusarium 2 disebut sebagai isolat 2, isolat genus Fusarium 3 disebut sebagai isolat 3, dan isolat genus Aspergillus disebut sebagai isolat 4.

Penelitian terhadap parameter warna dimulai dengan melakukan pengujian awal terhadap kandungan warna pada limbah batik. Warna dapat diamati secara visual (langsung), dengan membandingkan warna air sampel dengan warna standar. Air yang memiliki nilai kekeruhan rendah biasanya memiliki nilai warna tampak dan warna sesungguhnya yang sama dengan standar (APHA, 1976; Davis dan Cornwell, 1991 dalam Effendi, 2003).

Proses dekolorisasi keempat isolat diamati secara visual. Perlakuan mengakibatkan perubahan warna limbah yang semula coklat pekat menjadi jernih. Warna media pada isolat 1 mengalami perubahan berarti pada setiap perlakuan. Pada konsentrasi $100 \%$ berwarna kekuningan, pada konsentrasi $80 \%$ terlihat lebih jernih, begitupula pada konsentrasi lebih rendah warna semakin jernih. Tidak berbeda dengan isolat 1 , ketiga isolat lainnya mampu mendekolorisasi limbah batik. Hasil pengamatan secara visual menunjukkan bahwa semakin rendah konsentrasi semakin tinggi dekolorisasi.

Tes warna digunakan untuk menghitung kadar kekeruhan air yang berhubungan erat dengan konsentrasi yang mempengaruhi kecerahan air. Dilakukan pengenceran yang bertujuan mengetahui tingkat efisiensi kadar warna yang terkandung dalam limbah batik setelah melalui proses dekolorisasi. Sampel limbah industri sesudah proses dekolorisasi kemudian di analisa di laboratorium dengan menggunakan alat spectrofotometer. Dari penelitian ini menghasilkan data persentase dekolorisasi cair batik.

Hasil pengukuran persentase dekolorisasi keempat isolat sebagaimana terdaftar dalam Tabel 1 menunjukkan nilai persentase dekolorisasi yang semakin meningkat sejalan dengan diturunkannya perlakuan nilai konsentrasi limbah. Isolat 1 mampu mendekolorisasi limbah berturut-turut sebesar 69,346\%; 69,747\%; 73,334\%; 76,027\% dan $82,421 \%$ dengan konsentrasi limbah berturut-turut $100 \%, 80 \%, 60 \%, 40 \%$, $20 \%$. Isolat 2 mampu mendekolorisasi limbah berturut-turut sebesar $60,520 \%$; $62,700 \% ; \quad 67,513 \% ; \quad 68,659 \%$ dan $69,862 \%$, Isolat 3 sebesar $60,65 \%$; $63,158 \% ; \quad 64,075 \% ; \quad 64,992 \%$ dan $65,996 \%$, serta isolat 4 sebesar $60,695 \%$; $63,158 \% ; \quad 64,075 \% ; \quad 64,992 \%$ dan $65,996 \%$, dengan konsentrasi limbah berturut-turut $100 \%, 80 \%, 60 \%, 40 \%$, $20 \%$.

Tabel 1. Persentase dekolorisasi pada konsentrasi limbah yang berbeda

\begin{tabular}{|c|c|c|c|c|}
\hline \multirow{2}{*}{$\begin{array}{l}\text { Konsen- } \\
\text { trasi } \\
\text { limbah } \\
(\%)\end{array}$} & \multicolumn{4}{|c|}{ Persentase dekolorisasi (\%) } \\
\hline & $\begin{array}{l}\text { Isolat } \\
1\end{array}$ & $\begin{array}{l}\text { Isolat } \\
2\end{array}$ & $\begin{array}{l}\text { Isolat } \\
3\end{array}$ & $\begin{array}{l}\text { Isolat } \\
4\end{array}$ \\
\hline 100 & 69,346 & 60,520 & 60,65 & 60,695 \\
\hline 80 & 69,747 & 62,700 & 63,158 & 63,158 \\
\hline 60 & 73,334 & 67,513 & 64,075 & 64,075 \\
\hline 40 & 76,027 & 68,659 & 64,992 & 64,992 \\
\hline 20 & 82,421 & 69,862 & 65,996 & 65,996 \\
\hline
\end{tabular}

Warna air limbah menunjukkan kualitasnya, air limbah yang baru akan berwarna abu - abu, dan air limbah yang sudah basi atau busuk akan berwarna 
gelap (Mahida, 1984). Warna tertentu dapat menunjukkan adanya logam berat yang terkandung dalam air buangan (Tinsley dan Fransini, 1991). Air yang digunakan masyarakat umum diijinkan dengan kriteria bahwa air tidak lebih dari 75 unit warna (standar kobal-platinum), sedangkan yang disarankan tidak lebih dari 10 warna. Hal ini penting mengingat zat-zat warna banyak mengandung logam-logam berat yang bersifat toksis.

Warna juga merupakan senyawa yang dapat dipergunakan dalam bentuk larutan sehingga penampangnya berwarna. Warna air limbah dapat dibedakan menjadi dua, yaitu warna sejati dan warna semu. Warna yang disebabkan oleh warna organik yang mudah larut dan beberapa ion logam ini disebut warna sejati, jika air tersebut mengandung kekeruhan atau adanya bahan tersuspensi dan juga oleh penyebab warna sejati maka warna tersebut dikatakan warna semu dan juga karena adanya bahan-bahan yang tersuspensi yang termasuk koloid (Tchobanoglous, 1985).

Penurunan warna disebabkan oleh proses adsorbsi, dimana substansi molekul meninggalkan larutan limbah dan bergabung pada permukaan miselium. Proses adsorbsi disini berfungsi untuk menyisihkan senyawasenyawa aromatik dan senyawa organik terlarut. Pada umumnya warna yang digunakan pada industri batik Sokaraja adalah warna sintetis. Konsentrasi warna pada limbah cair setelah mendapat perlakuan dari jamur isolasi terjadi penurunan konsentrasi warna. Selain proses adsorbsi, diperkirakan system enzimatik ekstraseluler berperan dalam proses dekolorisasi ini.

Terjadinya proses dekolorisasi diduga karena adanya proses adsorbsi sebagai sistem non-enzimatik dilanjutkan dengan adanya kemampuan degradasi oleh isolat karena terjadinya aktivitas metabolisme dengan sistem enzimatik.
Wilkolazka et al. (2002) menyatakan bahwa fungi dapat mendekolorisasi struktur azo dengan sistem enzimatik dan non-enzimatik. Schiegel dan Schmit (1994) menyatakan bahwa penurunan intensitas warna oleh aktifitas isolat fungi diakibatkan oleh dua hal, yaitu karena adsorbsi dan sekresi enzim pada metabolismenya.

Metode

dekolorisasi menggunakan jamur hasil isolasi ini mampu menurunkan konsentrasi warna namun belum optimal. Warna sintetik limbah batik dapat diuraikan dengan menggunakan metode ini walaupun tidak seluruhnya. Penurunkan konsentrasi warna pada pengolahan limbah batik ini perlu dilakukan penelitian lanjutan dengan metode yang dimodifikasi.

\section{Kesimpulan}

1. Proses isolasi jamur indigenous dari limbah batik tulis di Kecamatan Sokaraja Kabupaten Banyumas menghasilkan 4 isolat yang berpotensi dalam mendekolorisasi, yaitu 3 isolat genus Fusarium, dan 1 isolat genus Aspergillus.

2. Jamur indigenous yang dihasilkan dapat digunakan untuk proses dekolorisasi limbah batik tulis dengan persentase dekolorisasi 60,520$82,421 \%$.

\section{Daftar Pustaka}

Alexopoulos, C. J.; C.W. Mims and M. Blackwell. 1996. Introductory Mycology. John Wiley \& Sons, Inc. New York.

Andayani W, Sumartono A. 1999. Aplikasi Radiasi Pengion dalam Penguraian Limbah Industri Radiolisis Larutan Standar Zat Warna Reaktif Cibacron Violet2r. Pusat Aplikasi Isotop dan Radiasi-Batan. Majalah Batan. 32(1):2. 
Anonim. 1996. Best Management Practices for Pollution Prevention in the Textile Industry. EPA (US Environmental Protection Agency). Office of Research and Development, A.S.

2003. Tekhnologi Pengendalian dan Pemanfaatan Limbah Tekstil.

www.forlink.dml.or.id/pteraph/t extile/121 htm. diakses pada Februari 2006.

APHA (American Public Health Association). 1976. Standart Methods for the Examination of Water and Waste Water $18^{\text {th }}$ edition. American Water Works Association. Water Pollution Control Federation, Washington D.C.

Atmaji , P., W, Purwanto dan E.P, Pramono. 1999. Daur Ulang Limbah Hasil Perwarnaan Tekstil. Jurnal Sains dan Tekhnologi Indonesia. Vol I No.4: pp. 3-15. Direktorat Tekhnologi Agroindustri. Bpp Tekkhnologi, Jakarta.

Awaluddin R., Darah S., Ibrahim C. D dan Uyub A. M. 2001. Decolorization of Commercially Available Synthetic Dyes by The White Rot Fungus Phanerochaete chrysosporium ME 446 (ATCC 34541). Proc. NSF workshop. Kuala Lumpur

Barnett H.L. and B. Hunter. 1972. Illustrated Genera of Imperfect Fungi. Burgess Publishing Company, U S A.
Bitton, G. 1994. Wastewater Microbiology. Jhon Willey and Sons, Inc. New York.

Dewi R. S. 2004. Potensi Isolat Fungi Limbah Industri Tekstil Sebagai Agen Pendekolorisasi Skripsi Tidak Dipublikasikan. Fakultas Biologi UNSOED, Purwokerto.

Effendi, H. 2003. Telaah Kualitas Air. Penerbit kanisius. Yogyakarta.

Gadd, G.M. 1992. Metal Tolerance Initiating Microbiology of Extreme Environment. University Press, Milton Keynes.

Gandjar I., R. A. Samson, K. T. Vermeulen, A. Oetari, I. Santoso. 1999. Pengenalan Kapang Tropik Umum. Yayasan Obor Indonesia. Jakarta

Mahida, U. N. 1984. Pencemaran Air dan Pemanfaatan Limbah Industri. CV. Rajawali, Jakarta.

Purnamasari, R. S. 2001. Pengaruh Penggunaan Faktor-Faktor Produksi Terhadap Jumlah dan Debit Serta aspek Finansian Pengolahan Limbah Cair Industri Tekstil. Skripsi Tidak Dipublikasikan. Jurusan IlmuIlmu Sosial Ekonomi Pertanian Fakultas Pertanian IPB, Bogor.

Robinson, T., McMullan, G., Marchant, R., and Nigam, P. 2001. Remediation of Dyes In Textile Effluent: A Critical Review On Current Treatment Technologies With A Proposed Alternative. Biores. Technol. 77: 247-255.

Sani, R. K. and Banerjee, U. C,. 1999. Decolorization 
Dekolorisasi Limbah Batik Tulis ... (Ratna Stia Dewi dan Sri Lestari)

Triphenylmethane Dyes And Textile And Dye-Stuff Effluent by Kurthia sp. Enzyme Microb. Technol., 24: 433-437.

Setiadi, T., Suwardiyono, and Wenten, I.G. 2002. Treatment of Textile Wastewater by a Coupling of Activated Sludge Process with Membrane Separation, Proc. Environmental Technology and Management Seminar. 9-10 Januari. Bandung.

Schiegel, H. G. dan Schmit, K. 1994. Mikrobiologi Umum. Diterjemahkan oleh Baskoro, R. M dan Watemena, J. R. Gadjah Mada University Press Yogyakarta.

Shore, J. 1996. Advance in Direct Dyes. Indian J. Fib. Text. Res (21): 129

Sullia, S. B. 2000. Fungal Diversity and Bioremidiation. Departemen of Microbiology \& Biotechnology. Bangalore University, Bangalore

Sumarmo dan Sumantri, I. 1999. Pengolahan Limbah Cair Industri Batik dengan Bak Anaerobik Bersekat. Dimensidimensi Vol 2

Suriawiria,U. 1996. Mikrobiologi Air dan Dasar- dasar Pengolahan Buangan secara Biologis. Alumni, Bandung.
Suriawiria,U. 1996. Mikrobiologi Air dan Dasar- dasar Pengolahan Buangan secara Biologis. Alumni, Bandung.

Tchobanoglous, G. and Schroeder, E.D. 1985. Waer Quality: Characteristics, Modeling , Modification, Addition. Wesly Reading. M.A.

Tinsley dan Fransini. 1991. Chemical Concep In Pollutant Behavior. Oregon State University. Carvallis.

Widyantoro, B., K.I.K, Jati., T, Setiadi dan I.G, Wanten. 2000. Sistem Bioreaktor Membran Aerob Untuk Pengolahan Limbah Cair Industri Tekstil. Seminar Nasional Rekayasa dan Proses. Jurusan Teknik Kimia ITB, Bandung.

Wilkolazka, A.J., J.KR. Dest, E. Malarczyk, W. Wardas, A. Leonowicz. 2002. Fungi and Their Ability to Decolourize Azo and Anthraquinonic Dyes. Enzyme and Microbial Technology (30). 566- 572

Wisnuprapto., E, Kardena dan W, Artha. 1999. Penyisihan Zat Warna Azo Ciro-16 dalam Modifikasi Proses Kontak-Stabilisasi Menggunakan Limbah Cair Industri Tempe. Jurnal Biosains. Vol. IV. No. 1. PPAU Bioteknologi dan Teknik Lingkungan ITB, Bandung. 